\title{
Red Blood Cells: Exchange, Transfuse, or Deplete
}

\author{
Georg Stussi $^{a}$ Andreas Buser $^{\mathrm{b}, \mathrm{c}}$ Andreas Holbro ${ }^{\mathrm{b}, \mathrm{c}}$ \\ ${ }^{a}$ Division of Hematology, Oncology Institute of Southern Switzerland, Bellinzona, Switzerland; ${ }^{b}$ Regional \\ Transfusion Service, Swiss Red Cross, Basel, Switzerland; ' Division of Hematology, University Hospital Basel, Basel, \\ Switzerland
}

\author{
Keywords \\ Transfusion · Red blood cell exchange . \\ Erythrocytapheresis $\cdot$ Red blood cell depletion · Sickle cell \\ anemia $\cdot$ Hematopoietic stem cell transplantation • \\ ABO phenotype $\cdot$ Malaria $\cdot$ Babesiosis
}

\begin{abstract}
Erythrocytapheresis, red blood cell (RBC) depletion, and RBC exchange transfusions are apheresis techniques used to rapidly lower the circulating RBC mass or to exchange the patient erythrocyte mass with donor RBC. Automated RBC exchange is performed using an apheresis device, while manual RBC exchange is based on sequential phlebotomies and isovolemic replacement. Compared to simple RBC transfusions, RBC exchange offers several advantages, e.g., a lower risk for iron accumulation and efficient control of pathological erythrocyte populations. Disadvantages are the higher costs of the procedure, the increased use of donor RBC, and the requirement of apheresis devices and trained hospital staff. The most frequent indication for RBC exchange is sickle cell disease (SCD). RBC exchange transfusions are standard treatment in SCD patients with a history of or a risk for acute stroke and are clinical options for other acute complications of SCD. The most common indication for RBC depletion is the removal of donor $\mathrm{RBC}$ from the bone marrow grafts in major ABO-incompatible allogeneic hematopoietic stem cell transplantation to avoid immediate hemolysis. Rare indications for RBC exchange are severe infections with intraerythrocytic pathogens such as malaria or babesiosis and severe erythrocytosis or hereditary hemochromatosis where the aim is to
\end{abstract}

rapidly decrease RBC populations or the iron content. However, only few high-quality studies are available looking at the efficacy of RBC exchange in the different disease entities, and treatment is often based on low levels of evidence and should therefore be decided in close collaboration with a transfusion medicine specialist.

(c) 2019 S. Karger AG, Basel

\section{Introduction}

Red blood cell (RBC) exchange is the replacement of a patient's RBC with homologous donor RBC and can be performed either manually or automated. It has the advantage over simple transfusions that the patient's RBC are replaced without increasing the hematocrit or exposing the patient to the risk of fluid overload or hyperviscosity [1]. RBC depletion in patients describes a procedure where $\mathrm{RBC}$ are removed and replaced with crystalloid or colloid solution, when necessary. This can be performed by different techniques, including sedimentation and apheresis. Erythrocytapheresis is a procedure in which $\mathrm{RBC}$ are removed from whole blood during the apheresis procedure and replaced by crystalloid or colloid solution [2]. In contrast, RBC depletion in stem cell products is indicated to avoid immediate hemolysis of the transplanted erythrocytes in the product during transplantation. Although the terms RBC exchange, RBC depletion, and erythrocytapheresis in the medical literature are often used interchangeably, they describe different therapeutic procedures. The main indications and the corre-

\section{KARGER}

(C) 2019 S. Karger AG, Basel 
Table 1. Level of evidence for RBC exchange transfusions [2]

\begin{tabular}{|c|c|c|c|}
\hline Disease & $\begin{array}{l}\text { Therapeutic } \\
\text { apheresis modality }\end{array}$ & $\begin{array}{l}\text { Level of } \\
\text { evidence }^{1}\end{array}$ & $\begin{array}{l}\text { Indication } \\
\text { category }^{2}\end{array}$ \\
\hline \multicolumn{4}{|l|}{ Sickle cell disease, acute complications } \\
\hline Acute stroke & RBC exchange & $1 \mathrm{C}$ & I \\
\hline Acute chest syndrome & RBC exchange & $1 \mathrm{C}$ & II \\
\hline Priapism & RBC exchange & $2 \mathrm{C}$ & III \\
\hline Multiorgan failure & RBC exchange & $2 \mathrm{C}$ & III \\
\hline Splenic/hepatic sequestration & RBC exchange & $2 \mathrm{C}$ & III \\
\hline \multicolumn{4}{|l|}{ Sickle cell disease, chronic complications } \\
\hline Stroke prophylaxis & RBC exchange & $1 \mathrm{~A}$ & I \\
\hline Pregnancy & RBC exchange & $2 \mathrm{~B}$ & II \\
\hline Recurrent vaso-occlusive pain crisis & RBC exchange & $2 \mathrm{~B}$ & II \\
\hline Preoperative management & RBC exchange & $2 \mathrm{~A}$ & III \\
\hline \multicolumn{4}{|l|}{ Allogeneic HSCT } \\
\hline Minor, prevention PLS & RBC exchange & $2 \mathrm{C}$ & III \\
\hline \multicolumn{4}{|l|}{ Infections } \\
\hline Malaria & RBC exchange & $2 \mathrm{~B}$ & III \\
\hline Babesiosis & RBC exchange & $2 \mathrm{C}$ & II \\
\hline Polycythemia vera & Erythrocytapheresis & $1 \mathrm{~B}$ & I \\
\hline Secondary erythrocytosis & Erythrocytapheresis & $1 \mathrm{C}$ & III \\
\hline Hereditary hemochromatosis & Erythrocytapheresis & $1 \mathrm{~B}$ & I \\
\hline Prevention and treatment of $\mathrm{RhD}$ alloimmunization & RBC exchange & $2 \mathrm{C}$ & III \\
\hline Erythopoietic porphyria, liver disease & RBC exchange & $2 \mathrm{C}$ & III \\
\hline \multicolumn{4}{|c|}{$\begin{array}{l}{ }^{1} \text { Level of evidence. 1A: strong recommendation, high-quality evidence; } 1 \mathrm{~B} \text { : strong recommendation, moder- } \\
\text { ate-quality evidence; 1C: strong recommendation, low or very low-quality evidence; } 2 \mathrm{~A} \text { : weak recommendation, } \\
\text { high-quality evidence; } 2 \mathrm{~B} \text { : weak recommendation, moderate-quality evidence; } 2 \mathrm{C} \text { : weak recommendation, low } \\
\text { or very low-quality evidence. }{ }^{2} \text { Indication category. I: disorders for which apheresis is accepted as first-line ther- } \\
\text { apy, either as a primary standalone treatment or in conjunction with other modes of treatment; II: disorders for } \\
\text { which apheresis is accepted as second-line therapy, either as a standalone treatment or in conjunction with oth- } \\
\text { er modes of treatment; III: optimum role of apheresis therapy is not established. Decision making should be in- } \\
\text { dividualized. }\end{array}$} \\
\hline
\end{tabular}

sponding level of evidence for these procedures are listed in Table 1.

Manual RBC exchange implies sequential phlebotomies and isovolemic replacement with crystalloids and donor RBC. It has been frequently used in the past. However, with the introduction of automated cell separators, it has lost some of its importance, but still might be applied in selected situations $[3,4]$. Automated RBC exchange is based on an apheresis procedure that separates $\mathrm{RBC}$ from other blood components. The RBC are selectively removed and replaced with donor RBC alone and/ or colloid/crystalloids solutions [2]. Automated apheresis instruments have substantially facilitated the collection and replacement procedures. Based on clinical data such as body weight, height, gender, age, initial and final hematocrit as well as average replacement fluid hematocrit and the fluid balance, the instruments calculate the exchange volumes [5]. Moreover, automated systems allow to determine the percentage of the patient's remaining erythrocytes (fraction of the remaining cells), which is of particular interest for the calculation of the remaining pathological erythrocytes in patients with sickle cell dis- ease (SCD), but also in malaria and babesiosis. The introduction of the automated RBC exchange procedure has substantially improved the standardization of the exchange procedures and can be performed with similar results on recent apheresis devices.

Table 2 lists the major advantages and disadvantages of the different transfusion methods. Simple transfusions are widely accessible and usually require peripheral venous access only. They can be performed without specialized technical equipment and specifically trained transfusion service staff. Therefore, they are very cost-effective and may be the only available option in many countries and smaller centers. Moreover, not all centers are able to offer RBC exchange transfusions as an emergency treatment, thus simple transfusions may still be the method of choice in these situations.

The main advantage of RBC exchange transfusions is the rapid reduction of pathological erythrocytes without increasing the hematocrit, fluid overload, and a reduced risk of iron accumulation, particularly in patients requiring chronic transfusion therapy. The procedure is faster and is associated with less hemodynamic stress for the 
Table 2. Comparison of transfusion methods [21]

\begin{tabular}{llll}
\hline & Simple transfusions & Manual RBC exchange & Automated RBC exchange \\
\hline Availability & Widespread & Widespread & Limited \\
Staff training & Minimal & Required & Required \\
Blood consumption & Low & Intermediate & High \\
Costs & Low & Intermediate & High \\
Hyperviscosity & Significant & Minimal & Minimal \\
HbS control & Limited & Intermediate & Best control \\
Procedure duration & Long & Long & Rapid \\
Procedure intervals & Short & Intermediate & Long (4-6 weeks) \\
Iron accumulation & High risk & Intermediate risk & Low risk \\
Alloimmunization & Lower risk & Intermediate risk & Higher risk \\
Venous access & Single venous & Double or single venous & High volume \\
& & & (CVC not mandatory) \\
\hline
\end{tabular}

CVC, central venous catheter.

patients. The main problems with RBC exchange are the high costs and the requirement for equipment and specialized staff. Adequate vascular access might be an issue, especially in patients with long-term exchanges and children of young age. Although most procedures can be performed using peripheral venous access, some patients may require a permanent central venous catheter or an arterio-venous fistula [6-8]. The question is of particular relevance for small pediatric patients, for whom simple transfusions are more frequently used than exchange transfusions, while the contrary is observed in adult patients [9]. RBC exchange transfusions require anticoagulation during the procedure, generally performed using citrate dextrose solutions.

$\mathrm{RBC}$ exchange transfusions are associated with a significantly higher blood requirement, because some erythrocytes transfused early are subsequently removed again by the apheresis procedure [9]. As a consequence of the higher blood consumption, some studies suggest a higher risk of alloimmunization and hemolytic transfusion reactions in patients receiving $\mathrm{RBC}$ exchange transfusions, although there are conflicting results in this regard [10-12]. In addition to the abovementioned disadvantages of RBC exchange, patients undergoing therapeutic apheresis are at risk for several general side effects of the apheresis procedure.

\section{RBC Exchange in Patients with SCD}

\section{Sickle Cell Disease}

SCD is an inherited disorder caused by a single mutation in the $\beta$-globin gene and encompasses homozygous mutations (S/S) as well as combined hemoglobinopathies such as a heterozygous mutation with a $\beta^{0}$-thalassemia $\left(S / \beta^{0}\right)$ or other mutations (e.g., HbSC), which may have a similar clinical presentation. It results in the formation of abnormal hemoglobin polymers when deoxygenated [13-15], with decreased deformability and the typical sickle form of the erythrocytes. Sickled erythrocytes possess many unfavorable physiologic properties and induce vascular changes that promote vaso-occlusion, infarction, hemolysis, and inflammation. SCD is a multisystem disorder associated with repetitive episodes of acute illness, organ damage, and often devastating pain attacks [16]. Acute manifestations of SCD are vaso-occlusive crisis, acute pain syndrome, organ infarction, and hemolytic anemia.

\section{Transfusion Therapy in SCD}

The current pillars in the treatment of SCD are hydroxyurea and RBC transfusions, which are increasingly used both in pediatric and adult patients [17-19]. The main objectives of RBC transfusions in SCD patients are (1) correction of anemia, (2) reduction of sickle cell hemoglobin (HbS), (3) suppression of defective RBC and thus HbS production, and (4) reduction of hemolysis. Sickle cell blood has an intrinsically increased viscosity, especially if the $\mathrm{HbS}$ is deoxygenated and oxygenation is improved at lower hemoglobin levels. Hence, to avoid hyperviscosity the posttransfusion, the hemoglobin value should not exceed the baseline value of the patient. Moreover, aged RBC concentrates might increase storage lesions of the transfused erythrocytes, suggesting that transfusion of fresh blood might be beneficial in patients with SCD $[17,18]$. However, data regarding the impact of age for erythrocyte transfusions is somewhat controversial $[19,20]$. For a thorough review of transfusion therapy in SCD we refer to the excellent recently published literature and guidelines [21-23].

The potential benefits of RBC transfusions should be carefully balanced against the risks, e.g., iron overload 
and alloimmunization. To reduce the latter risk, all SCD patients should have an extended RBC phenotype (ABO, Rhesus, Kell, MNS-, Duffy-, and Kidd) before initiating transfusion therapy [24]. Many institutions recommend transfusion of $\mathrm{ABO}$ compatible, extended Rhesus and Kell antigen matched, leukocyte-depleted RBC products, while others try to consider additional antigens (i.e., MNS-, Duffy-, and Kidd blood groups) at the expense of increased costs. A recent review analyzing the genotyping strategy of the RHD and RHCE system shows a high frequency of partial $\mathrm{Rh}$ antigens in the French population, indicating a benefit of genotyping in patients with newly diagnosed SCD or known high-responders (patients with high probability to develop allo-antibodies due to multiple transfusions [25]. In some countries with high SCD prevalence sickle cell testing is recommended in all blood donors. In patients on chronic transfusion therapy, the transfusion history should be evaluated regularly, at least once a year, and patients should receive appropriate vaccinations against hepatitis B infections [23].

The decision for simple or RBC exchange transfusion requires a close collaboration with the transfusion service. The choice of the appropriate method should take into consideration the risk for hyperviscosity and alloimmunization, the iron balance, the venous access, and the availability of the respective therapy modalities. The final decision often depends on the current hemoglobin level, the steady state hemoglobin level of the patient's preexisting anemia, the percentage of $\mathrm{HbS}$, as well as the general clinical condition [23]. A recent consensus conference held by the American Society for Apheresis on the role of $\mathrm{RBC}$ exchange transfusions in the management of patients with SCD evaluated the level of consensus among different specialists in transfusion medicine in SCD patients [26].

In patients with pretransfusion anemia below their individual hemoglobin baseline values, simple transfusions might be the best, easiest, and cheapest option aiming at a posttransfusion hemoglobin value not exceeding 100 $\mathrm{g} / \mathrm{L}$, or $10-20 \mathrm{~g} / \mathrm{L}$ above the baseline level. RBC exchange transfusions are indicated in patients with increased $\mathrm{HbS}$ without severe anemia compared to the baseline hemoglobin level. The best posttransfusion hemoglobin level should be analyzed in each individual patient based on the clinical situation and the previous history of SCDrelated complications [23].

\section{Acute Stroke}

Acute stroke is one of the most devastating complications in SCD patients, often already affecting patients at pediatric age. Without preventive measures, approximately $11 \%$ of the patients experience a stroke by 20 years of age [27]. Stroke in SCD is associated with a vasculopathy of the distal carotid and the cerebral arteries, and trans- cranial duplex sonography of the carotid or cerebral arteries is the method of choice for early detection of the increased vascular flow velocity [28].

$\mathrm{RBC}$ transfusions to decrease and maintain a low $\mathrm{HbS}$ level are essential for both preventing first and recurrent stroke episodes $[29,30]$. In the stroke prevention trial in SCD (STOP), asymptomatic patients with increased mean blood flow as measured by transcranial Doppler sonography were randomized to receive either standard of care or regular transfusions with the aim of maintaining $\mathrm{HbS}$ at $\leq 30 \%$ and hemoglobin not higher than $120 \mathrm{~g} / \mathrm{L}$ before transfusion [29]. Simple RBC transfusions or RBC exchange transfusion were both allowed in this trial. The RBC transfusion strategy resulted in an impressive 92\% reduction of the risk of stroke, leading to early termination of the trial. In this regard, it is of interest that although the costs for automated RBC exchange transfusions are considerable, its use leads to cost savings for global health costs due to a reduction of hospitalization days due to SCD-associated complications [31].

Likewise, in children with silent intracerebral infarctions diagnosed on magnetic resonance imaging, chronic transfusion therapy can reduce the risk of secondary strokes [30, 32]. In the Silent Cerebral Infarct Transfusion (SIT) multicenter clinical trial, children with SCD-related silent cerebral infarcts received either standard of care (observation) or chronic transfusion therapy with the aim of maintaining hemoglobin $>90 \mathrm{~g} / \mathrm{L}$ and the $\mathrm{HbS} \leq 30 \%$. The observation group had more secondary episodes, both clinical strokes and new or enlarged silent cerebral infarctions. Moreover, fewer cases of acute vaso-occlusive pain, acute chest syndromes, priapism, and avascular bone necrosis were observed in the transfusion group. Not surprisingly, however, patients on chronic transfusion therapy had a five-fold higher risk of transfusion complications and a fourteen-fold higher risk of iron overload.

Discontinuation of transfusions once established has proved to be difficult. In the STOP II trial children with initially abnormal blood flow who had received at least 30 months of transfusion therapy and had a normalization of cerebral blood flow were randomized to continue or discontinue chronic transfusion therapy [33]. The trial had to be stopped early because of an increased stroke rate in the discontinuation group. A recently published phase III noninferiority study analyzed the switch to hydroxyurea in children on chronic transfusion therapy [34]. Patients with abnormal vascular flow, but without severe vasculopathy, who had received at least 1 year (mean 4 years) of transfusion therapy were randomized to continue transfusion therapy or hydroxyurea at the maximally tolerated dose. Hydroxyurea proved to be noninferior to transfusion therapy and thus can replace transfusions in patients without severe vasculopathy. In line with that, 
some patients with normalization of transcranial Doppler velocity might be switched to hydroxyurea provided there is trimestral Doppler follow-up and immediate restart of transfusions in the case of reversion [35].

Taken together, these studies indicate that the current standard of care for prevention of primary and secondary stroke is to maintain $\mathrm{HbS}$ at $<30 \%$ by long-term transfusions both in children and in adult patients. Since RBC exchange transfusions seem to be associated with a lower risk of subsequent stroke episodes, it is the method of choice in patients with acute stroke episodes [36]. Hydroxyurea treatment should be considered for the primary prevention of stroke in children with high transcranial Doppler velocity without severe vasculopathy after at least 1 year of transfusion therapy. RBC transfusions should also be offered to patients with silent cerebral infarctions.

Acute Chest Syndrome and Other SCD Complications

Acute chest syndrome is one of the most common and serious clinical complications and a frequent cause for hospitalization of SCD patients [37]. The full clinical picture, defined by respiratory problems (chest pain, fever, tachypnea, wheezing, or cough) and a pulmonary alveolar infiltrate on a chest X-ray may develop only during hospitalization [37]. Primary treatment involves broadspectrum antibiotics, bronchodilators, and oxygen support as well as hydroxyurea. RBC transfusions are usually not indicated as first-line treatment but are a therapeutic option in resistant acute chest syndrome. To date, it is not clear whether RBC exchange transfusions are preferable to simple transfusions [38].

The frequency of acute painful crises is individual and reflects the current disease activity. They often cause prolonged hospitalization, as well as important morbidity and increased mortality in patients with SCD. Both in the STOP and the SIT trial, the incidence of acute painful crises was reduced by RBC transfusions. However, hydroxyurea is also very effective in reducing the painful crises and therefore should be considered as first-line therapy. Simple or RBC exchange transfusions should be considered in patients resistant or intolerant to hydroxyurea. Transfusions might be life-saving in acute aplastic crisis, splenic or hepatic sequestration, as well as multiorgan failure. The transfusion can be administered as simple or exchange transfusion depending on the clinical condition of the patient and the pretransfusion hemoglobin values.

\section{Perioperative Management of SCD Patients}

Surgery and anesthesia are associated with an increased risk for acute SCD complications. Many sickle cell crises are caused by vascular alterations due to acute or chronic inflammation. Surgical interventions including anesthetic procedures may cause hypotension, local hypoxia, acidosis, and inflammation, thereby triggering sickling of erythrocytes and vaso-occlusive crises in approximately $20 \%$ of all patients with a 1-month overall mortality of $1.1 \%$ [39]. Therefore, patients with SCD undergoing a surgical intervention should be rigorously hydrated.

The main objective of perioperative management of patients with SCD is to prevent the development of vasoocclusive crises, stroke, and acute coronary syndromes during and after surgical interventions. There is a broad consensus that patients before elective surgery should receive RBC transfusions. The Transfusions Alternatives Preoperatively in Sickle Cell Disease (TAPS) study clearly demonstrated that preoperative transfusions are associated with an almost four-fold decrease of the risk of perioperative SCD-related complications, in particular acute coronary syndrome [40]. In patients with hemoglobin $<90 \mathrm{~g} / \mathrm{L}$, simple transfusions are preferred over exchange transfusions aiming at a posttransfusion hemoglobin level of $>100 \mathrm{~g} / \mathrm{L}$. A randomized controlled study showed that a conservative perioperative management (objective: hemoglobin $>100 \mathrm{~g} / \mathrm{L}$ ) was as effective in preventing perioperative complications as an aggressive preoperative transfusion management (objective: $\mathrm{HbS}<$ $30 \%$ ), and the conservative strategy resulted in only half the number of transfusion complications [41].

\section{ABO-Incompatible Hematopoietic Stem Cell Transplantation}

Since HLA and ABO antigens are independently inherited, allogeneic hematopoietic stem cell transplantation (HSCT) is routinely performed across the ABO blood group barrier [42, 43]. Three groups of ABO mismatch can be distinguished in HSCT: minor, major, and bidirectional ABO incompatibility. Minor ABO incompatibility, e.g., from an O-type donor to an A-type recipient, is characterized by the ability of donor B-lymphocytes to produce anti-recipient isohemagglutinins. In contrast, major ABO-incompatible HSCT, e.g., from an A-type donor to an O-type recipient, is characterized by the presence of preformed anti-donor isohemagglutinins. In bidirectional $\mathrm{ABO}$ incompatibility, e.g., A-type donor to a B-type recipient, a combination of both the major and minor ABO blood group barriers must be overcome [44].

Major ABO-incompatible HSCT may be complicated by severe hemolysis immediately after the infusion of the stem cell product. This immediate hemolysis is caused by preexisting isohemagglutinins in the recipient that bind to and eventually eliminate transplanted donor erythrocytes. Isohemagglutinins can be removed from the recipient prior to HSCT by plasmapheresis and/or by slow infusions of incompatible donor-type RBC [45]. Alterna- 
tively, RBC can be removed from the stem cell product by RBC depletion. Stem cell products collected by peripheral blood apheresis usually contain small amounts of donor erythrocytes and, due to the low risk of hemolysis, do not require further processing. In contrast, bone marrowderived stem cell products contain approximately 25 $35 \%$ donor erythrocytes. Here, RBC depletion is a standard procedure to avoid hemolysis and can be achieved by density centrifugation (sedimentation) or automatically using an apheresis device $[46,47]$. While this technology has been used for many years in major ABO-incompatible bone marrow transplant recipients, it has partially lost its importance in the last decade due to the preferential use of peripheral blood stem cell products. However, with the renewed interest in bone marrow stem cell products in the context of haploidentical HSCT, the processing of $\mathrm{ABO}$-incompatible bone marrow products will be increasingly used again [48]. The choice of the technique largely depends on the center's experience. While historically many centers have used sedimentation for RBC depletion, currently RBC depletion is predominantly done by apheresis as it is less complicated and laborious. Comparison of different depletion technologies has shown that there are slight differences with regard to erythrocyte depletion and the recovery of mononuclear cells [46]. Throughout the years, several apheresis devices have been used to perform RBC depletion prior to stem cell transplantation, achieving robust erythrocyte depletion [49-52].

An important immunohematological complication after minor or bidirectional ABO-incompatible HSCT is delayed hemolysis due to donor-derived passenger lymphocyte syndrome (PLS), which produces antibodies against the patient's remaining erythrocytes $[53,54]$. It is characterized by a delayed hemolysis, 2-4 weeks (typically 7-10 days) after HSCT, and occurs in $10-15 \%$ of patients after minor ABO-incompatible HSCT. Although rare, it can cause severe hemolysis and may lead to multiorgan failure and eventually death of the patients. Hemolysis persists until the residual recipient $\mathrm{RBC}$ are destroyed or replaced by donor type and by transfused RBC. Risk factors for PLS include peripheral blood stem cells, a donor with blood group $\mathrm{O}$ and recipient with blood group A, cyclosporine alone as GVHD prophylaxis, and reduced-intensity conditioning.

To avoid PLS, patient erythrocytes can be prophylactically removed by $\mathrm{RBC}$ exchange and substituted with $\mathrm{O}$ erythrocytes with a goal of less than $35 \%$ of residual RBC. This concept has been tested in a single-center study analyzing minor or bidirectional ABO-incompatible HSCT receiving prophylactic $\mathrm{RBC}$ exchange transfusions with historical controls [55]. All patients were transplanted with reduced-intensity conditioning and mostly peripheral blood stem cells. To avoid immediate hemolysis, plasma was reduced from bone marrow products. The incidence of PLS was high in the historical control (5/10 patients) and 3 patients died of transplant-related mortality during the period of hemolysis. For this reason, prophylactic $\mathrm{RBC}$ exchange transfusions prior to minor or bidirectional ABO-incompatible HSCT were started, replacing 1-1.5 times the patient blood volume with a median of 8 RBC concentrates. Thus, the incidence of severe hemolysis and transplant-related mortality was reduced in minor $\mathrm{ABO}$-incompatible reduced-intensity conditioning HSCT undergoing $\mathrm{RBC}$ exchange, while there was no difference in the incidence of GVHD and overall survival.

A second retrospective single-center study analyzed prophylactic $\mathrm{RBC}$ exchange transfusion in minor and bidirectional ABO-incompatible HSCT. In contrast to the previous study, prophylactic RBC exchange was performed on day 4 after allogeneic HSCT and only in patients deemed to be high risk according to the presence of predefined risk factors. It is of note that in the RBC exchange group, a higher number of patients received reduced-intensity conditioning regimens due to a change in the transplant practice in this period. The latter study showed a statistically nonsignificant trend towards fewer cases of severe hemolysis in the exchange group, while there was no difference in overall survival. Patients in the $\mathrm{RBC}$ exchange group required twice as many RBC transfusions compared to the historical group [56].

However, although there might be a slight improvement in the incidence of severe hemolysis, RBC exchange has not been widely accepted among transplant centers due to practical reasons, the potential side effects in this particular patient population, and the relatively inefficient exchange procedure [53].

\section{RBC Exchange in Infectious Diseases}

\section{Malaria}

Malaria represents a significant health problem and is associated with a considerable mortality despite adequate treatment. While most cases with acute malaria have relatively low parasitic burden, approximately $10 \%$ of the patients are classified as severe cases with a high infectious load [57]. In these cases, the therapeutic aim is to rapidly reduce the parasitic load.

Standard treatment for malaria consists of intravenous antibiotics and supportive care. Adjunct RBC exchange transfusions may have at least 3 beneficial effects: (1) the rapid reduction of parasitemia, (2) improvement in the rheologic properties of the blood and oxygen delivery, and (3) reduction of intravascular hemolysis and cytokines. RBC exchange in malaria patients has been introduced more than 40 years ago for 
patients with severe parasitemia (>10\%), mostly with plasmodium falciparum. However, to date no randomized clinical trial has ever been performed. Several case reports or smaller case series analyzed the benefit of added RBC exchange with variable results. In 2002 a meta-analysis concluded that there was no benefit of the adjunct therapy and the authors did not recommend the use of RBC exchange in these clinical situations [58]. A more recent case series has looked again at the issue. A single-center study retrospectively analyzed 146 cases of malaria diagnosed at the Vienna University Hospital from 2002 to 2010 [57]. Of these, 16 patients were classified as having severe malaria, and 11 patients were candidates for and 5 patients underwent $\mathrm{RBC}$ exchange. The procedure was safe and led to a rapid reduction of the parasitic load. However, a thorough analysis of the efficacy of the procedure was not possible due to the low number of patients.

In 2013 the Center for Disease Control and Prevention (CDC) performed a retrospective analysis, in which 101 patients receiving $\mathrm{RBC}$ exchange transfusions were matched to 314 patients not receiving exchange transfusions [59]. Despite faster parasite clearance, there was no evidence for efficacy and, as a consequence, the CDC no longer recommends RBC exchange transfusions as an adjunct procedure for the treatment of malaria due also to the availability of highly efficient antimalarial drugs. Moreover, most of the patients with severe malaria live in countries without medical access to RBC exchange procedures and/or pathogen-free (i.e., Plasmodium) blood products.

\section{Babesiosis}

Babesiosis is a tick-borne infectious disease caused by intraerythrocytic protozoa [60]. More than 100 different Babesia species are known, but mostly they infect wild and domestic animals, while only few cause infections in humans. In the USA, most cases are caused by Babesia microti, while in Europe, many cases have been attributed to infection with Babesia venatorum. Transmission in humans is mainly caused by ticks, but in some cases it may also arise during pregnancy and as a transfusion-associated event [61]. Babesia infect red cells causing hemolysis and hypoxia. The clinical manifestations vary considerably, ranging from subclinical infections to life-threatening acute infections with acute respiratory failures, acute hemolysis, and disseminated intravascular coagulation. Immunocompromised patients are at risk for severe and relapsing or persistent forms of babesiosis and require extensive antibiotic treatments [62].

The primary treatment for babesiosis is an antibiotic combination, e.g., atovaquone and azithromycin or clindamycin and quinine for 7-10 days [63]. Adjunct $\mathrm{RBC}$ exchange is indicated in immunocompromised or splenectomized patients with high parasitic load (>10\%) and a severe clinical picture consisting of hemolysis, or end-organ disease in the liver, kidney, or lungs [64]. Some reports suggest performing RBC exchange in elderly, pregnant, or pediatric patients with severe babesiosis and in the presence of concomitant disseminated intravascular coagulation or coma. A recent review of blood bank charts from 19 patients receiving RBC exchange transfusions for babesiosis showed that the procedure could reduce the parasitic load by $75 \%$. However, there was no evidence that $\mathrm{RBC}$ exchange transfusions could reduce the number of hospital days or mortality [65]. Hence, the available data for adjunct RBC exchange in patients with babesiosis is even less than in patients with malaria, therefore the indication and treatment procedures are poorly defined and mostly deduced from malaria $[64,66]$. In patients with post-babesiosis warm-antibody autoimmune hemolytic anemia, $\mathrm{RBC}$ exchange does not seem to have an impact on the outcome [67].

\section{Rare Indications}

Polycythemia vera is a malignant disease belonging to the myeloproliferative neoplasms. The absolute increase in RBC results in hyperviscosity and tissue hypoxia. Polycythemia vera patients are generally treated with isovolemic phlebotomy and low-dose aspirin, and high-risk patients require cytoreductive therapy. Repetitive phlebotomies gradually lower the disease-associated symptoms and the risk of thromboembolic complications [68]. Some rare patients may present with severe microcirculatory symptoms or hemodynamic instability and require rapid lowering of the hematocrit. Erythrocytapheresis, like isovolemic phlebotomy, corrects the hyperviscosity by lowering the hematocrit value, but removes a higher erythrocyte volume than isovolemic phlebotomy and therefore reduces the time and number of procedures required to achieve the target hematocrit [69-71]. Hence, it may be considered in hemodynamically unstable patients or in patients who require an efficient and fast decrease of red cell mass.

Hereditary hemochromatosis is the most common inherited genetic disease in Europe and is often associated with a mutation in the HFE gene, although several others may also be involved [72, 73]. Patients with a homozygous HFE mutation are at risk for iron accumulation resulting in chronic iron overload and if untreated, eventually organ damage.

The standard therapy for hereditary hemochromatosis is repetitive isovolemic phlebotomy, which in general efficiently lowers the iron overload. However, erythrocytapheresis removes erythrocytes more efficiently and therefore might offer a possibility to reduce the iron 
overload faster in patients with symptomatic iron overload. Two randomized trials compared phlebotomy and erythrocytapheresis as initial therapy in patients with newly diagnosed hereditary hemochromatosis or during maintenance phase after having reached the therapeutic range $[74,75]$. Both studies showed that the number of treatment procedures could be significantly reduced using erythrocytapheresis (9 vs. 27 treatment procedures during initial therapy, and 3.3 vs. 1.9 treatment procedures/year during the maintenance phase). Given the clearly lower number of treatment procedures during the initial phase, the overall costs of the two treatments were similar, while the costs with erythrocytapheresis were higher during maintenance. Another study analyzed asymptomatic blood donors with elevated ferritin levels. Upon confirmation of hereditary hemochromatosis, patients underwent either phlebotomies or erythrocytapheresis [76]. This study did not show a benefit for erythrocytapheresis, but a higher risk of procedural complications.

\section{Summary}

Erythrocytapheresis, RBC depletion, and RBC exchange transfusions are efficient therapeutic modalities to lower the hematocrit or to transfuse without increasing the hematocrit or causing iron overload. The most important indications for RBC exchange transfusions are patients with stroke in the setting of SCD. RBC depletion by sedimentation or apheresis is mainly used during processing of $\mathrm{ABO}$-incompatible bone marrow products. Most indications are based on few studies in the literature and decisions have to be based on personal experience, availability of staff and equipment, and the individual patient situation. The transfusion medicine specialists should be integrated early in the decision process.

\section{Disclosure Statement}

The authors declare no financial conflicts.

\section{References}

1 Driss F, Hequet O. Red blood cell exchange techniques and methods. Transfus Apher Sci. 2019 Apr;58(2):132-5.

2 Padmanabhan A, Connelly-Smith L, Aqui N, Balogun RA, Klingel R, Meyer E, et al. Guidelines on the Use of Therapeutic Apheresis in Clinical Practice - Evidence-Based Approach from the Writing Committee of the American Society for Apheresis: The Eighth Special Issue. J Clin Apher. 2019 Jun;34(3):171-354.

3 Kuo KH, Ward R, Kaya B, Howard J, Telfer P. A comparison of chronic manual and automated red blood cell exchange transfusion in sickle cell disease patients. Br J Haematol. 2015 Aug;170(3):425-8.

4 Swerdlow PS. Red cell exchange in sickle cell disease. Hematology Am Soc Hematol Educ Program. 2006;2006(1):48-53.

5 Staley E, Hoang ST, Liu H, Pham HP. A brief review of common mathematical calculations in therapeutic apheresis. J Clin Apher. 2019 Oct;34(5):607-12.

6 Delville M, Manceau S, Ait Abdallah N, Stolba J, Awad S, Damy T, et al. Arterio-venous fistula for automated red blood cells exchange in patients with sickle cell disease: complications and outcomes. Am J Hematol. 2017 Feb; 92(2):136-40.

7 Putensen D, Leverett D, Patel B, Rivera J. Is peripheral access for apheresis procedures underutilized in clinical practice?-A single centre experience. J Clin Apher. 2017 Dec;32(6):553-9.

8 Otrock ZK, Thibodeaux SR, Jackups R Jr. Vascular access for red blood cell exchange. Transfusion. 2018 Feb;58 Suppl 1:569-79.

9 Kelly S, Quirolo K, Marsh A, Neumayr L, Garcia A, Custer B. Erythrocytapheresis for chronic transfusion therapy in sickle cell disease: survey of current practices and review of the literature. Transfusion. 2016 Nov;56(11): 2877-88.
10 Kim HC. Red cell exchange: special focus on sickle cell disease. Hematology Am Soc Hematol Educ Program. 2014 Dec;2014(1):4506.

11 Michot JM, Driss F, Guitton C, Moh Klaren J, Lefebvre F, Chamillard X, et al. Immunohematologic tolerance of chronic transfusion exchanges with erythrocytapheresis in sickle cell disease. Transfusion. 2015 Feb;55(2): 357-63.

12 Matteocci A, Pierelli L. Red blood cell alloimmunization in sickle cell disease and in thalassaemia: current status, future perspectives and potential role of molecular typing. Vox Sang. 2014 Apr;106(3):197-208.

13 Ware RE, de Montalembert M, Tshilolo L, Abboud MR. Sickle cell disease. Lancet. 2017 Jul;390(10091):311-23.

14 Piel FB, Steinberg MH, Rees DC. Sickle Cell Disease. N Engl J Med. 2017 Apr;376(16): 1561-73.

15 Rees DC, Williams TN, Gladwin MT. Sicklecell disease. Lancet. 2010 Dec;376(9757): 2018-31.

16 Platt OS, Thorington BD, Brambilla DJ, Milner PF, Rosse WF, Vichinsky E, et al. Pain in sickle cell disease. Rates and risk factors. N Engl J Med. 1991 Jul;325(1):11-6.

17 Chadebech P, de Ménorval MA, Bodivit G, Mekontso-Dessap A, Pakdaman S, Jouard A, et al. Evidence of benefits from using fresh and cryopreserved blood to transfuse patients with acute sickle cell disease. Transfusion. 2016 Jul;56(7):1730-8.

18 Gehrke S, Shah N, Gamboni F, Kamyszek R, Srinivasan AJ, Gray A, et al. Metabolic impact of red blood cell exchange with rejuvenated red blood cells in sickle cell patients. Transfusion. 2019 Oct;59(10):3102-12.

19 Fields ME, Hulbert ML, Chen L, Berlin AN, Jackups R, Spinella PC. Red blood cell storage duration is not associated with clinical outcomes for acute chest syndrome in children with sickle cell disease. Transfusion. 2015 Nov;55(11):2714-21.

20 Blumberg N. Transfusing fresh red blood cells might be dangerous. BMJ. 2019 Aug; 366:14968.

21 Howard J. Sickle cell disease: when and how to transfuse. Hematology Am Soc Hematol Educ Program. 2016 Dec;2016(1):625-31.

22 Davis BA, Allard S, Qureshi A, Porter JB, Pancham S, Win N, et al.; British Society for Haematology. Guidelines on red cell transfusion in sickle cell disease Part II: indications for transfusion. Br J Haematol. 2017 Jan;176(2): 192-209.

23 Davis BA, Allard S, Qureshi A, Porter JB, Pancham S, Win N, et al.; British Committee for Standards in Haematology. Guidelines on red cell transfusion in sickle cell disease. Part I: principles and laboratory aspects. $\mathrm{Br} \mathrm{J} \mathrm{Hae}-$ matol. 2017 Jan;176(2):179-91.

24 Raba M. Selecting red blood cell units to perform RBCX in patients with sickle cell disease. Transfus Apher Sci. 2019 Apr;58(2): 142-6.

25 Floch A, Tournamille C, Chami B, Pirenne F. Genotyping in Sickle Cell Disease Patients: the French Strategy. Transfus Med Hemother. 2018 Jul;45(4):264-70.

26 Sarode R, Ballas SK, Garcia A, Kim HC, King $\mathrm{K}$, Sachais B, et al. Red blood cell exchange: 2015 American Society for Apheresis consensus conference on the management of patients with sickle cell disease. J Clin Apher. 2017 Oct;32(5):342-67.

27 Ohene-Frempong K, Weiner SJ, Sleeper LA, Miller ST, Embury S, Moohr JW, et al. Cerebrovascular accidents in sickle cell disease: rates and risk factors. Blood. 1998 Jan;91(1): 288-94. 
28 Platt OS. Preventing stroke in sickle cell anemia. N Engl J Med. 2005 Dec;353(26):27435 .

29 Adams RJ, McKie VC, Hsu L, Files B, Vichinsky E, Pegelow C, et al. Prevention of a first stroke by transfusions in children with sickle cell anemia and abnormal results on transcranial Doppler ultrasonography. N Engl J Med. 1998 Jul;339(1):5-11.

30 DeBaun MR, Gordon M, McKinstry RC, Noetzel MJ, White DA, Sarnaik SA, et al. Controlled trial of transfusions for silent cerebral infarcts in sickle cell anemia. N Engl J Med. 2014 Aug;371(8):699-710.

31 Tsitsikas DA, Ekong A, Berg L, Hartzenberg J, Sirigireddy B, Lewis N, et al. A 5-year cost analysis of automated red cell exchange transfusion for the management of recurrent painful crises in adult patients with sickle cell disease. Transfus Apher Sci. 2017 Jun;56(3):4669.

32 King AA, Noetzel M, White DA, McKinstry $\mathrm{RC}$, Debaun MR. Blood transfusion therapy is feasible in a clinical trial setting in children with sickle cell disease and silent cerebral infarcts. Pediatr Blood Cancer. 2008 Mar;50(3): 599-602.

33 Adams RJ, Brambilla D; Optimizing Primary Stroke Prevention in Sickle Cell Anemia (STOP 2) Trial Investigators. Discontinuing prophylactic transfusions used to prevent stroke in sickle cell disease. N Engl J Med. 2005 Dec;353(26):2769-78.

34 Ware RE, Davis BR, Schultz WH, Brown RC, Aygun B, Sarnaik S, et al. Hydroxycarbamide versus chronic transfusion for maintenance of transcranial Doppler flow velocities in children with sickle cell anaemia-TCD With Transfusions Changing to Hydroxyurea (TWiTCH): a multicentre, open-label, phase 3, non-inferiority trial. Lancet. 2016 Feb; 387(10019):661-70.

35 Bernaudin F, Verlhac S, Arnaud C, Kamdem A, Hau I, Leveillé E, et al. Long-term treatment follow-up of children with sickle cell disease monitored with abnormal transcranial Doppler velocities. Blood. 2016 Apr; 127(14):1814-22.

36 Hulbert ML, Scothorn DJ, Panepinto JA, Scott JP, Buchanan GR, Sarnaik S, et al. Exchange blood transfusion compared with simple transfusion for first overt stroke is associated with a lower risk of subsequent stroke: a retrospective cohort study of 137 children with sickle cell anemia. J Pediatr. 2006 Nov;149(5):710-2.

37 Vichinsky EP, Neumayr LD, Earles AN, Williams R, Lennette ET, Dean D, et al.; National Acute Chest Syndrome Study Group. Causes and outcomes of the acute chest syndrome in sickle cell disease. N Engl J Med. 2000 Jun; 342(25):1855-65.

38 Turner JM, Kaplan JB, Cohen HW, Billett $\mathrm{HH}$. Exchange versus simple transfusion for acute chest syndrome in sickle cell anemia adults. Transfusion. 2009 May;49(5): 863-8.

39 Koshy M, Weiner SJ, Miller ST, Sleeper LA, Vichinsky E, Brown AK, et al.; Cooperative Study of Sickle Cell Diseases. Surgery and anesthesia in sickle cell disease. Blood. 1995 Nov;86(10):3676-84.
40 Howard J, Malfroy M, Llewelyn C, Choo L, Hodge R, Johnson T, et al. The Transfusion Alternatives Preoperatively in Sickle Cell Disease (TAPS) study: a randomised, controlled, multicentre clinical trial. Lancet. 2013 Mar; 381(9870):930-8.

41 Vichinsky EP, Haberkern CM, Neumayr L, Earles AN, Black D, Koshy M, et al.; The Preoperative Transfusion in Sickle Cell Disease Study Group. A comparison of conservative and aggressive transfusion regimens in the perioperative management of sickle cell disease. N Engl J Med. 1995 Jul;333(4): 206-13.

42 Stussi G, Halter J, Schanz U, Seebach JD. ABO-histo blood group incompatibility in hematopoietic stem cell and solid organ transplantation. Transfus Apher Sci. 2006 Aug;35(1):59-69.

43 Klumpp TR. Immunohematologic complications of bone marrow transplantation. Bone Marrow Transplant. 1991 Sep;8(3):159-70.

44 Holbro A, Passweg JR. Management of hemolytic anemia following allogeneic stem cell transplantation. Hematology Am Soc Hematol Educ Program. 2015;2015(1):378-84

45 Stussi G, Halter J, Bucheli E, Valli PV, Seebach L, Gmür J, et al. Prevention of pure red cell aplasia after major or bidirectional $\mathrm{ABO}$ blood group incompatible hematopoietic stem cell transplantation by pretransplant reduction of host anti-donor isoagglutinins. Haematologica. 2009 Feb;94(2):239-48.

46 Sorg N, Poppe C, Bunos M, Wingenfeld E, Hümmer C, Krämer A, et al. Red blood cell depletion from bone marrow and peripheral blood buffy coat: a comparison of two new and three established technologies. Transfusion. 2015 Jun;55(6):1275-82.

47 Braine HG, Sensenbrenner LL, Wright SK, Tutschka PJ, Saral R, Santos GW. Bone marrow transplantation with major ABO blood group incompatibility using erythrocyte depletion of marrow prior to infusion. Blood. 1982 Aug;60(2):420-5.

48 Passweg JR, Baldomero H, Bader P, Bonini C, Duarte RF, Dufour C, et al. Use of haploidentical stem cell transplantation continues to increase: the 2015 European Society for Blood and Marrow Transplant activity survey report. Bone Marrow Transplant. 2017 Jun; 52(6):811-7

49 Witt V, Beiglböck E, Fritsch G. Bone marrow processing with the AMICUS ${ }^{\mathrm{TM}}$ separator system. J Clin Apher. 2011;26(4):195-9.

50 Kim-Wanner SZ, Bug G, Steinmann J, Ajib S, Sorg N, Poppe C, et al. Erythrocyte depletion from bone marrow: performance evaluation after 50 clinical-scale depletions with Spectra Optia BMC. J Transl Med. 2017 Aug;15(1): 174

51 Soydan E, Ayyildiz E, Dalva K, Topçuoğlu P, Tol M, Arslan Ö, et al. Impact of harvest product volume in erythrocyte depletion of allogeneic or autologous bone marrow using COBE spectra. Transfus Apher Sci. 2007 Jun;36(3): 269-73.

52 Veljković D, Nonković OŠ, Radonjić Z, Kuzmanović M, Zečević Z. Bone marrow processing for transplantation using Cobe Spectra cell separator. Transfus Apher Sci. 2013 Jun;48(3):359-63.
53 Booth GS, Gehrie EA, Bolan CD, Savani BN. Clinical guide to $\mathrm{ABO}$-incompatible allogeneic stem cell transplantation. Biol Blood Marrow Transplant. 2013 Aug;19(8):1152-8.

54 Bolan C, Childs R, Procter J, Barrett A, Leitman S. Massive immune haemolysis after allogeneic peripheral blood stem cell transplantation with minor $\mathrm{ABO}$ incompatibility. $\mathrm{Br} \mathrm{J}$ Haematol. 2001 Mar;112(3):787-95.

55 Worel N, Greinix HT, Supper V, Leitner G, Mitterbauer M, Rabitsch W, et al. Prophylactic red blood cell exchange for prevention of severe immune hemolysis in minor $\mathrm{ABO}$ mismatched allogeneic peripheral blood progenitor cell transplantation after reduced-intensity conditioning. Transfusion. 2007 Aug; 47(8):1494-502.

56 Cunard R, Marquez II, Ball ED, Nelson CL, Corringham S, Clopton $\mathrm{P}$, et al. Prophylactic red blood cell exchange for $\mathrm{ABO}$-mismatched hematopoietic progenitor cell transplants. Transfusion. 2014 Jul;54(7):1857-63.

57 Auer-Hackenberg L, Staudinger T, Bojic A, Locker G, Leitner GC, Graninger W, et al. Automated red blood cell exchange as an adjunctive treatment for severe Plasmodium falciparum malaria at the Vienna General Hospital in Austria: a retrospective cohort study. Malar J. 2012 May;11(1):158.

58 Riddle MS, Jackson JL, Sanders JW, Blazes DL. Exchange transfusion as an adjunct therapy in severe Plasmodium falciparum malaria: a meta-analysis. Clin Infect Dis. 2002 May; 34(9):1192-8

59 Tan KR, Wiegand RE, Arguin PM. Exchange transfusion for severe malaria: evidence base and literature review. Clin Infect Dis. 2013 Oct;57(7):923-8

60 Vannier E, Krause PJ. Human babesiosis. N Engl J Med. 2012 Jun;366(25):2397-407.

61 MoritzED, Winton CS, Tonnetti L, Townsend RL, Berardi VP, Hewins ME, et al. Screening for Babesia microti in the U.S. Blood Supply. N Engl J Med. 2016 Dec;375(23):2236-45.

62 Krause PJ, Gewurz BE, Hill D, Marty FM, Vannier E, Foppa IM, et al. Persistent and relapsing babesiosis in immunocompromised patients. Clin Infect Dis. 2008 Feb;46(3):3706.

63 Krause PJ, Lepore T, Sikand VK, Gadbaw J Jr, Burke G, Telford SR 3rd, et al. Atovaquone and azithromycin for the treatment of babesiosis. N Engl J Med. 2000 Nov;343(20):14548.

64 Guru PK, O Horo JC, Lehrke HD, Winters JL, Wilson JW. Exchange transfusion for babesiosis when, how, and how long? Indian J Crit Care Med. 2016 Nov;20(11):674-6.

65 Nixon CP, Park S, Nixon CE, Reece RM, Sweeney JD. Adjunctive treatment of clinically severe babesiosis with red blood cell exchange: a case series of nineteen patients. Transfusion. 2019 Aug;59(8):2629-35.

66 Spaete J, Patrozou E, Rich JD, Sweeney JD. Red cell exchange transfusion for babesiosis in Rhode Island. J Clin Apher. 2009;24(3):97105.

67 Woolley AE, Montgomery MW, Savage WJ, Achebe MO, Dunford K, Villeda S, et al. PostBabesiosis Warm Autoimmune Hemolytic Anemia. N Engl J Med. 2017 Mar;376(10): 939-46. 
68 Marchioli R, Finazzi G, Specchia G, Cacciola R, Cavazzina R, Cilloni D, et al.; CYTO-PV Collaborative Group. Cardiovascular events and intensity of treatment in polycythemia vera. N Engl J Med. 2013 Jan;368(1):22-33.

69 Choe WH, Park BG, Lee KH, Lee JH, Lee JH, Kwon SW. Automated double red-cell phlebotomy for the treatment of erythrocytosis. J Clin Apher. 2012 Nov;27(5):255-9.

70 Evers D, Kerkhoffs JL, Van Egmond L, Schipperus MR, Wijermans PW. The efficiency of therapeutic erythrocytapheresis compared to phlebotomy: a mathematical tool for predicting response in hereditary hemochromatosis, polycythemia vera, and secondary erythrocytosis. J Clin Apher. 2014 Jun;29(3):133-8.
71 Vecchio S, Leonardo P, Musuraca V, D'Ettoris A, Geremicca W. A comparison of the results obtained with traditional phlebotomy and with therapeutic erythrocytapheresis in patients with erythrocytosis. Blood Transfus. 2007 Jan;5(1):20-3.

72 Powell LW, Seckington RC, Deugnier Y. Haemochromatosis. Lancet. 2016 Aug; 388(10045):706-16.

73 Pietrangelo A. Hereditary hemochromatosis-a new look at an old disease. N Engl J Med. 2004 Jun;350(23):2383-97.

74 Rombout-Sestrienkova E, Winkens B, Essers BA, Nieman FH, Noord PA, Janssen MC, et al. Erythrocytapheresis versus phlebotomy in the maintenance treatment of HFE hemochromatosis patients: results from a randomized crossover trial. Transfusion. 2016 Jan; 56(1):261-70.
75 Rombout-Sestrienkova E, Nieman FH, Essers BA, van Noord PA, Janssen MC, van Deursen $\mathrm{CT}$, et al. Erythrocytapheresis versus phlebotomy in the initial treatment of HFE hemochromatosis patients: results from a randomized trial. Transfusion. 2012 Mar;52(3):4707.

76 Stefashyna O, Stern M, Infanti L, Holbro A, Tichelli A, Buser A, et al. Pattern of care of blood donors with early-uncomplicated hereditary haemochromatosis in a Swiss blood donation centre. Vox Sang. 2014 Feb;106(2): $111-7$. 